К ВОПРОСУ О ТЕОРЕТИЧЕСКИХ ОСНОВАНИЯХ ИЗУЧЕНИЯ ПОВЕДЕНИЯ ПРЕДПЕНСИОНЕРОВ В УСЯОВИЯХ ЦИФРОВИЗАЦИИ ОБЩЕСТВА*

\title{
ADAPTIVE BEHAVIOR OF PREPENSIONERS IN THE CONDITIONS OF PANDEMIC, DIGITALIZATION AND COMPUTERIZATION OF SOCIETY
}

\section{НИКОЯЕНКО Наталия Александровна}

Водгоградский государственный университет,

г. Волгоград, Россия

E-mail: nikolenko@volsu.ru

\section{NIKOLENKO Natalia A.}

Volgograd State University,

Volgograd, Russia

E-mail: nikolenko@volsu.ru

(c) Николенко Н. А., Дулина Н. В., Ситникова Я. И., 2021.

* Исследование выполнено при финансовой поддержке РФФИ и администрации Волгоградской области в рамках научного проекта № 19-411-340005 «Социальная поддержка предпенсионеров на региональном рынке труда в условиях цифровой экономики». 


\section{ДУ ЛИНА Надежда Васидьевна}

Волгоградский государственный университет, Водгоград, Россия

E-mail:nv-dulina@volsu.ru

\section{СИТНИКОВА Яна Игоревна}

Волгоградский государственный университет, г. Волгоград, Россия АНО СОН «СОЦИУМ», г. Волгоград, Россия E-mail: jana3194@mail.ru

Аннотация. B статье акцентируется внимание на поведенческих стратегиях граждан предпенсионного возраста в условиях современной реальности, сложность и специифика которой объясняется наличием ряда объективных обстоятельств, рассматриваемых в качестве факторов влияния внешней среды. Отмечается, что наиболее значимыми из них для представителей указанной соичиальной группы являются: увеличение продолжительности периода трудовой деятельности в связи с принятием новой пенсионной реформы и повышением пенсионного возраста 6 России; введение год назад режима социальной изоляции изза распространения пандемии COVID-19 и его последствий отразившихся на состоянии экономики, рынке труда и занятости населения, создании социальной напряженности из-за увеличения количества безработных; на изменении повседневного образа жизни, условий и характере тру да, в том числе на требованиях, предъявляемых к квалификациии сотрудников, переведенных в формат удаленной работы. На основе теоретического анализа научных работ показан процесс адаптации постепенно сменяющих друг друга этапов, следует обратить внимание на разнообразие видов адаптации и возможность их сочетаний; рассмотреть особенности активной, пассивной и активно-пассивной стратегий адаптивного поведения индивидов, а также принять во внимание необходиость использования комплексного подхода при оценке эффективности адаптации.

Ключевые слова: предпенсионеры, циифровизация $и$ компьютеризаиия общества, пандемия коронавируса COVID-19, виды, критерии адаптации; адаптацуионное поведение; типы адаптационных стратегий.
DULINA Nadezhda V.

Volgograd State University, Volgograd, Russia

E-mail: nv-dulina@volsu.ru

\section{SITNIKOVA Yana I.}

Volgograd State University, Volgograd, Russia, ANO "SOCIUM", Volgograd, Russia E-mail: jana3194@mail.ru

Abstract. The article focuses on the behavioral strategies of citizens of pre-retirement age in the conditions of modern reality, the complexity and specificity of which is explained by the presence of a number of objective circumstances considered as factors of influence of the external environment. It is noted that the most significant of them for the representatives of this social group are: an increase in the duration of the period of labor activity in connection with the adoption of a new pension reform and an increase in the retirement age in Russia; the introduction a year ago of a regime of social isolation due to the spread of the COVID-19 pandemic and its consequences, which affected the state of the economy, the labor market and employment of the population, creating social tension due to an increase in the number of unemployed; on changes in the daily lifestyle, conditions and nature of work, including on the requirements for the qualifications of employees transferred to the format of remote work. Based on the theoretical analysis of scientific works, the process of adaptation is show as gradually replacing each other stages, to pay attention to the variety of types of adaptation and the possibility of their combination; consider the features of active, passive and active-passive strategies of adaptive behavior the need to use an integrated approach when assessing the effectiveness of adaptation.

Keywords: pre-retirees, digitalization and computerization of society, the COVID-19 coronavirus pandemic, stages of the adaptation process; types, adaptation criteria; adaptive behavior; types of adaptation strategies.

\section{Введение}

История человечества, пожалуй, не знает времени, когда процессы, происходящие в обществе, не отражались бы на жизнедеятельности дюдей. Однако события всего XX века и первой четверти XXI века поражают воображение беспощадностью того, как они буквально врывадись в повседневную жизнь людей, изменяя существующие подитические и экономические системы, низвергая и создавая культурные и духовные ценности, вынуждая людей приспосабливаться (адаптироваться) к последствиям происходящих перемен. Среди значимых событий, в первую очередь, следует упомянуть две мировые войны, политические перевороты, экономические кризисы, научно-техническую революцию, переход к «Индустрии 4.0», распространение и применение интернет-технологий во всех сферах общественной жизни и др. Далеко не последнее место в этом перечне занимают эпидемии глобального масштаба испанка и, конечно же, пандемия коронавируса COVID-19.

Динамика событий нашего времени диктует необходимость изучения поведенческих практик индивидов, расширения категориадьного аппарата, 
исподьзуемого в рамках подходов изучения адаптационного поведения индивидов, и акцентуации внимания как на самом процессе социальной адаптации, так и на особенностях мотивационных побуждений индивидов к действию данного типа, раскрытию его характера и описанию резудьтатов. При этом следует подчеркнуть, что протекание адаптационных процессов у представителей разных социальных групп (и даже у отдельных их представителей) имеет свои особенности, несмотря на то, что все социально активные слои населения (в виду указанных выше причин) испытывают вдияние вызовов внешней среды.

Предметом научного интереса является специфическая социальная группа - предпенсионеры (Васильева Е. Г., Николенко Н. А., 2020), своеобразие положения которой проявляется в том, что представитеди этой группы должны в современных условиях конкурировать на рынках профессий, труда и занятости с более мододыми дюдьми. Вряд ли стоит особо доказывать, что уровень осведомленности об использовании новых технологий у предпенсионеров, мягко говоря, несколько иной, да и физическое состояние лиц этой возрастной группы (вдияющих на работоспособность, утомдяемость и т. д.) имеет в силу естественных причин определенные отличия.

Введенные на период пандемии меры социальной изоляции (например, самоизоляция людей в возрасте старше 65 лет) дишь обостриди условия конкурентной борьбы на рынке труда. К работникам в одночасье в силу объективных причин - перевода в режим работы онлайн - повысидись требования в плане владения и использования интернет-технологий; определенную роль стали играть наличие или отсутствие персональных компьютеров дибо иных технических средств, а также условий для работы (на рабочем месте или дома), позводяющих или не позводяющих выполнять предписанные профессиональные функции качественно и в срок.

Другими словами, кардинальная перестройка стиля и образа жизни, изменение характера организации труда и требований к выполняемым профессиональным функциям в прошедшем 2020 г. не только подтвердили непрерывность изменений, происходящих в социадьных системах (Р. Дарендорф и др.), но и нагдядно продемонстрировади возможность их неожиданного протекания в интенсивном режиме. Это обстоятельство нельзя не учитывать при изучении проблем, связанных с существованием и жизнедеятельностью общества, среди которых выделенная авторами статьи - поведенческие стратегии индивидов в ситуации адаптации к условиям возникающей новой реальности, - явдяется значимой по причине непреходящей актуальности.

Последствия социальных изменений, детерминирующих изменения в поведении индивидов, оказывают влияние как на самих индивидов, так и на общество в целом. В этой связи становится очевидной необходимость изучения адаптационных процессов с целью облегчения вхождения индивидов в новую реальность. Такая попытка и была предпринята авторами статьи, объектом выполненного исследования выступила весьма не однородная по своему составу группа предпенсионеров.

Однако прежде чем представить результаты исследования, необходимо представить размышления о теоретических основания выполненной работы. 


\section{Научно-теоретические основания к изучению адаптационного поведения}

В научной литературе проблемам адаптации личности к условиям внешней среды уделялось и уделяется достаточно пристальное внимание. Представители разных научных направлений благодаря своим исследованиям обращают внимание на особенности адаптации социальных систем, а также индивидов в разных сферах жизнедеятельности, расширяя научное представление об этом сложном и многогранном социальном феномене. Проблемы адаптации рассматриваются в разных плоскостях. На макроуровне анадизируются аспекты адаптации общества к глобальным политическим и экономическим преобразованиям (Двойникова 2017 и др.); на микроуровне: подитическая адаптация индивида (Макаренко 2016; Маркина 2008; Шишкин 2015 и др.), адаптация в информационно-правовом пространстве (Терещенко, Васильев 2013), к социальной среде (Дукашенко 2014), к социально-экономических условиям (Терещенко 2006), к изменениям рынка труда (Капица 2009); социально-психологическая (Иванова 2014; Хаустова 2016) и трудовая адаптация (Котдова, Попова 2014; Макайкина 2019; Слепцова, Сапрунова 2020).

В ряде работ адаптация рассматривается как научно-исследовательский феномен (Долгова 2009; Скрылева 2007), как процесс развития дичности (Максимов 2013), в рамках которого индивид вовлекается или сталкивается с раздичными видами адаптации: информационной, социально-экономической, профессиональной; антроповиталистической (сочетающей виталистическую и психодогическую адаптацию) (Трошина 2014), производственной и внепроизводственной (Кибанов, Дуракова 2019) и др.

Кроме того, объектом изучения становится поведение разных социальных групп, оказавшихся в новых ддя них социальных реалиях: адаптация студентов в вузовской среде (Двойникова 2015), адаптация персонала в организации и молодых специалистов, в частности (Смирнова, Кочеткова, Коротина 2017), сотрудников сидовых структур (Дукашенко 2018), социальнопсихологическая реадаптация участников боевых действий (Караяни, Караяни 2014), адаптация представителей старшего поколения к политическим, социально-экономическим и культурным условиям современного общества высокоскоростных трансформаций (Максимова, Максимов 2015), социальная активность пожилых людей (Васильева, Скобелина, Николенко, Дулина 2018), одиночество как способ существования (Максимова, Маховицкая, Ничиженова, Соболева 2016) и т. д.

Приведенный список источников позводяет понять, что аспекты изучения феномена адаптации весьма разнообразны и охватывают вопросы как общетеоретического, так и частного порядка, ориентированные на опредеиенные категории населения, среди которых социальная группа современных педпенсионеров с плавающими возрастными границами занимает определенное место. Так, в научной и публицистической дитературе помимо вышеотмеченных присутствуют материалы, касающиеся:

- уточнения правового статуса современных предпенсионеров (Чупрасова 2019; Васильева, Николенко 2020), 
- разъяснений положений законодательных актов и государственных программ, направленных на поддержку граждан предпенсионного возраста на рынке труда и занятости (Иванов 2019; Широких 2019),

- планирования их профессиональной деятельности (Усаева 2020), анализа проблем трудоустройства (Садкова 2019), в том числе и самозанятости в условиях цифрового общества (Николенко 2020),

- проявдения скрытой дискриминации граждан данной возрастной группы на рынке труда (Черных, Тарасова, Сырчин 2020),

- положения предпенсионеров на региональном рынке труда и занятости в условиях пандемии (Николенко, Серова 2020; Черных, Тарасова, Сырчин 2020),

- подготовки к выходу на пенсию (Демиш 2015) и др.

Однако, несмотря на большой спектр рассматриваемых авторами проблем, на взгляд автора статьи, остаются недостаточно раскрытыми аспекты, связанные с мотивацией выбора предпенсионерами адаптационных стратегий в условиях пандемии (как варианта экстремальной ситуации) и цифровизации общества, которые актуадизировали необходимость переосмысления отношения к профессиональной деятельности, возможностям самореадизации и, возможно, дальнейшим жизненным перспективам.

Рассматривая адаптационный процесс на микро- и макросоциальном уровнях, необходимость изучения особенностей его динамики (проявляемой в смене этапов), факторов вдияния на него и критериев оценки не вызывает сомнения. Следует обратить внимание, что взаимозависимость и взаимовдияние указанных выше уровней проявляет себя с неоспоримой очевидностью. На макросоциальном уровне отражаются происходящие в обществе процессы, касающиеся всего социума. Например, в период пандемии это массовая заболеваемость населения, последствия вынужденных мер по введению режима самоизоляции (на которые уже обращалось внимание): ухудшение экономической ситуации в стране и мире, увеличение кодичества безработных граждан, обострение конкуренции на рынках труда и занятости; ускорение процессов цифровой трансформации общества и др. И индивид вынужден реагировать на особенности происходящих процессов. На микросоциальном уровне, представляющим собой сочетание разных сред (Капица 2009) или миров (Болтански, Тевено 2000), в которых осуществляется деятельность людей, адаптация происходит к условиям жизни, в которых индивид непосредственно пребывает. В рассматриваемом периоде вынужденной социальной самоизоляции это проявилось в изменении стиля и образа жизни, затронув сферы быта, досуга, учебы, труда; в отношении к профессиональной деятельности, квалификационные требования к которой в ряде случаев стали иными под влиянием ускорения процессов цифровизации и компьютеризации общества в ситуации пандемии. А также в ряде случаев отразилось на психологическом самочувствии, материальном положении индивидов, на их поведении в изменившейся ситуации при выборе адаптационных стратегий и его результатах.

Все вышеотмеченное подтверждает правидьность высказанной еще четверть века назад точки зрения на понимание адаптации, с одной стороны, 
как процесса взаимодействия субъектов (индивидов, групп, институтов) с изменяющейся социальной средой, в ходе которого постепенно согласуются требования и ожидания вовлеченных в него акторов, а с другой стороны, как его результата. При этом показателем благополучной адаптации предлагается рассматривать приспособление индивида любой степени (а не тодько отражающей улучшение прежнего положения) к условиям новой социальной реальности. Возможности данного приспособления могут рассматриваться в качестве ресурсного потенциала макросреды для ее воспроизводства и перехода в новую стадию развития (Шабанова 1995: 82).

Среди видов адаптации выдедяют социальную (вхождение в новую социальную среду, ценности и нормы которой постепенно принимаются и осваиваются индивидом), профессиональную (приобретение новых знаний, формирование компетенций, умений и навыков, необходимых для работы в изменившейся среде), производственную (усвоение норм трудовой деятельности, установление и развитие отношений для делового сотрудничества), психофизиологическую (приспособление к новым условиям работы, психическим и физическим нагрузкам), организационную (освоение и приспособление субъекта к новой системе социальной иди внутригрупповой стратификации); функциональную (выполнение новых социальных ролей), экономическую (принятие уровня и сроков выплаты зарплаты и других материальных поощрений за выполненные функциональные обязанности), социиальнопсихологическую (адаптация к новому трудовому коллективу на фоне освоения условий труда) (Кибанов, Дуракова 2019) и как ее разновидности: социально-психодогическую адаптацию конструктивного и деструктивного типов (Двойникова 2017); антроповиталистическую (объединяющую витадистическую и психологическую виды адаптации) (Трошина 2014).

Однако данным перечнем список видов адаптаций не ограничивается, так как в зависимости от мотивации субъекта выделяют адаптацию добровольную и вынужденную, которые в свою очередь могут быть охарактеризованы в качестве активной или пассивной (Шабанова 1995: 83), а при рассмотрении ее результатов (оцененных с позиций объективных и субъективных приобретений/потерь индивидами «чего-дибо практически весомого» в процессе адаптации) - прогрессивную (созидательную) и регрессивную (разрушительную) (Шабанова 1995: 84-85).

Анализ перечисленных видов адаптации позводяет обратить внимание на то, что адаптация - процесс сложный, который в зависимости от того, в каких сферах индивид задействован, может происходить в разных условиях. Одновременно проявдяя себя в двух плоскостях: сознания и поведения. Более того, ни один из вышеперечисленных видов на практике не существует изодировано от других. Комбинация видов адаптаций зависит от складывающейся ситуации. K примеру, в экстремальных условиях пандемии COVID19 диапазон видов адаптации, вкдюченных в комбинационные варианты, был достаточно широк (охватывал сразу, как было отмечено выше, и сферу труда, и сферу быта, и сферу досуга, и сферу учебы и др.), что осложняло процесс приспособления к изменившимся условиям жизни «на разных 
уровнях функциональной организации человека: психофизиологическом, психологическом, социально-психологическом» (Дуцко 2008: 205).

В свою очередь следует отметить, что на каждом ярусе (уровне) адаптации (макросоциальном и микросоциальном) действуют свои регуляторы (факторы) социальной адаптации (социетальные, статусные, социальнопсихологические, поведенческие), которые вдияют на особенности прохождения индивидами этапов адаптации, и отражаются на ее результатах адаптации, ее эффективности.

Несмотря на разнообразие представленных в научной дитературе названий этапов адаптации, канвой их содержательных частей (несмотря на то, что авторы делают акценты на том иди ином аспекте) остается одно: изменение среды требует времени на осознание происходящего, на оценку индивидом своего ресурсного потенциала, на выбор модели адаптационного поведения и предположительную оценку его результатов. В подтверждение можно привести несколько вариантов названий этапов процесса адаптации: а) «ознакомление», «приспособление», «ассимиляция» (Смирнова, Кочеткова, Коротина 2017: 60); б) «адаптационный шок», «мобилизация адаптационных ресурсов», «ответ на «вызов среды» - в случае диаметрадьного расхождения «старых» и «новых» норм, ценностей, условий жизнедеятельности; «уравновешивание», «псевдоадаптация», «приноравдивание» при определенном совпадении ценностей (Щепаньский 1969); в) «активизационный» предполагающий мобилизацию всех сил и ресурсов организма для успешной адаптации; «поисковый», в ходе которого осуществляется выбор стратегии действия в проблемной ситуации; и «результативный», демонстрирующий итог адаптации (Хохрина, Машанов, Ростовцева 2015).

При этом необходимо подчеркнуть, что поведение субъектов адаптации зависит от их индивидуальных особенностей (состояния здоровья, психофизических свойств, сложившейся системы жизненных ценностей и ориентаций, взгдядов на развитие жизненных сценариев, надичия жизненного опыта, социальной активности, волевых качеств, умений организовывать свой труд, самостоятельно и творческих работать, самооценка, самоконтродь, уверенность в собственных силах и др. и т. д.), социально-демографических показателей (возраста, пола, семейного положения и т. д.), особенностей содержания и организации деятельности, а также характеристики среды, в которой она осуществляется. Другими словами, от факторов внутреннего и внешнего порядка (Дуцко 2008).

Сдедует также придерживаться позиции исследователей, которые предлагают преодолеть узость трактовок пассивного и активного видов адаптации, сводимую дишь к выявлению вдияния дибо внешней среды на субъекта, дибо субъекта на нее (Максимов 2013; Реан, Кудашев, Баранов 2008). По их мнению, явно недостаточно трактовать деятельность субъекта в категориях активной адаптации (если он пытается преобразовать внешнюю среду лишь в целях достижения наилучших результатов своего приспособления), или пассивной адаптации (когда им прилагается минимум усилий для приспособления, а цели преобразования внешней среды вообще не ставятся). 
При этом в качестве защиты более глубокого понимания пассивной и активной адаптации приводится объяснение, что проявдяемый субъектом в процессе приспособления к новым условиям существования даже минимум усилий вполне допустимо рассматривать и трактовать как определенную активность, но с низкой степенью выраженности прилежания. Поэтому следует обращать внимание на направленность (вектор) проявления активности, которая отмечена в обоих видах (или типах) адаптации: «активном» и «пассивном» (Реан 1994). А так как проявление направлений активного вдияния дичности может быть два: наружу: на внешнюю среду (ее освоение и / или приспособление к ней) и внутрь: на изменение структуры дичности (инструментальных поведенческих стереотипов, прежних установок, формирование мотиваций к освоению новых знаний и т. д.), то и виды адаптации должны анализироваться в этих плоскостях. В первом случае, как «тип активного преобразования среды», а во втором - как «тип активного самоприспособления к среде» (Максимов 2013).

Однако и здесь все не так однозначно, как может показаться на первый взгляд. Приспособление к внешней среде может выражаться как в действиях по ее преобразованию, так и в пассивном подчинении новым нормам социальной среды, что может привести к неудовлетворенности и психологическому дискомфорту (Реан, Кудашев, Баранов 2008), к ритуализму, который Р. Мертон относил к деструктивной адаптации. И поэтому подобная стратегия адаптивного поведения может быть охарактеризована как «тип пассивного приспособления».

Если же индивид наоборот внутренне перестраивается, отказывается от того, что мешает ему развиваться в новых условиях, изменяется сам и направляет усидия на изменение внешней среды, то можно утверждать, что выбранная стратегия адаптивного поведения представдяет собой «тип активного приспособления». Если же индивид сознательно направляет вектор своей активности на бегство от новой социальной реальности, не ставит и не решает возникающие проблемные ситуации (не ставит перед собой задач решать возникающие проблемные ситуации), то в этом случае он действует в рамках стратегии ретритизма. Что, однако, может быть оценено двояко: общество будет считать подобное поведение неадаптивным. А индивид, к примеру, находящийся на иждивении у государства бомж, будет оценивать его как вподне адаптивное.

Другими словами, значимость вектора направленности активности адаптации внутрь является весьма существенной, так как именно на уровне сознания дичности происходит формирование трех эдементов жизненного пути: смысла жизни, жизненной позиции, жизненной диний (АбульхановаСлавская 1991). Смысл жизни и жизненную динию определяют терминальные ценности-цели (или жизненные ценности), а жизненную позицию (рассматриваемую и как «потенциал развития личности», и как «способ осуществления жизни») определяют инструментальные ценности-средства. Жизненная позиция проявляется в самоопределении личности, формируется под вдиянием ее активности и постепенно реадизуется как диния жизни 
(Абульханова-Славская 1991). Если учесть, что на практике достаточно часто встречается сочетание указанных выше типов активности («наружу» /«вовне»/ и «внутрь»), что позволило А. А. Реану, отмечая эффективность и целесообразность их вариативного сочетания, выделить третий вид адаптации: вероятностно-комбинированный (Реан 1994).

Что касается стратегий поведения индивидов в процессе адаптации, то выделенные Н. Н. Мельниковой основания для их классификации (контактность-избегание; Направленность изменений / среды и самого индивида/; его активность-пассивность) вподне объясняют особенности восьми предиоженных стратегий адаптивного поведения: «1. Активный, контактный, направленный вовне (активное изменение среды) 2. Активный, контактный, направленный вовнутрь (активное изменение себя - внутренняя перестройка личности). 3. Активный, избегающий, направленный вовне (активный уход из среды и поиск новой: возможны изменения места жительства, работы, учебы, смена круга друзей, образование новой семьи). 4. Активный, избегающий, направленный вовнутрь (активный уход от контакта со средой и погружение во внутренний мир: избегание контакта со средой посредством замыкания во внутреннем, «своем» мире: возможно с использованием дополнительных средств (алкоголя, наркотиков) для изменения внутреннего состояния). 5. Пассивный, контактный, направленный вовне (пассивная репрезентация себя: упрямое отстаивание своей позиции. Стремление самоутвердиться, отстоять свое «Я» часто реализуется через стратегию пассивной репрезентации себя). 6. Пассивный, контактный, направленный вовнутрь (пассивное подчинение условиям среды, не предполагают глубокой иичностной перестройки. Наиболее яркое проявление этой стратегии - внешнее конформное поведение.). 7. Пассивный, избегающий, направленный вовне (пассивное выжидание внешних изменений выжидая внешних изменений. Откладывая решение важных проблем на более поздний срок, человек временно ограничивает свои контакты со средой, оставаясь, по возможности, незаметным, «замороженным» до появления удовлетворяющих его условий.). 8. Пассивный, избегающий, направленный вовнутрь (пассивно ожидание внутренних изменений: настроения, появление ощущения внутренней готовности и т.д. Человек ожидает благоприятных изменений не вовне, а внутри себя») (2001:20). В более укрупненном варианте, вышеописанные стратегии могут быть представлены тремя основными: активной, пассивной и активно-пассивной (Хохрина, Машанов, Ростовцева 2015).

Что касается критериев оценки выбранной стратегии адаптационного поведения, то они, как справеддиво замечает Е. А. Ауцко, могут быть разделены на группы в зависимости от позиции оценивающего и отражать «соответствие требованиям среды (внешний критерий) или же потребностям индивида (внутренний критерий)» (2008). При этом критерием позитивной адаптации могут служить «не только выживаемость человека и нахождение места в социально-профессионадьной структуре, но и общий уровень здоровья, способность развиваться в соответствии со своим потенциалом жизнедеятельности, субъективное чувство самоуважения» (Максимов 2013). 
Другими словами, тодько «комплексный подход, рассматривающий эффективность адаптации с точки зрения как человека, так и среды на всех уровнях функциональной организации человека: психофизиологическом, психологическом и социально-психологическом» (Дуцко 2008), может быть принят в качестве приемлемого.

Таким образом, анализ и систематизация вышеприведенных научных источников позволяет представить процесс адаптации как постепенно сменяющих друг друга этапов, обратить внимание на разнообразие видов адаптации и возможность их сочетаний; рассмотреть особенности активной, пассивной и активно-пассивной стратегий адаптивного поведения индивидов, а также принять во внимание необходимость исподьзования комплексного подхода при оценке эффективности адаптации. Проведенное социодогическое исследование подтвердило теоретические выводы авторов статьи, но это уже материал для других размышлений и другой статьи.

\section{ИСПОЯЬЗОВАННЫЕ ИСТОЧНИКИ}

1. Альбуханова-Славская, К. А. Стратегия жизни / К. А. Альбуханова-Славская. - М.: Мысль, 1991. - 301 с.

2. Адаптивный -Адаптационный -Адаптированный. Раздичие в значениях // Инфопедия для углубления знаний. - Режим доступа: URL: https://infopedia.su/4x1f29.html (дата обращения: 5.05.2021 г.).

3. Болтански, А. Социология критической способности / Д. Болтански, А. Тевено // Журнал социологии и социальной антропологии. - 2000. - Т. III. - № 3. -С. 66-83.

4. Васильева, Е. Г. Кто такие предпенсионеры? К вопросу о социальном статусе группы / Е. Г. Васильева, Н. А. Николенко // Logos et Praxis. Серия 7: Философия. Социология и социальные технологии. - 2020. - Т. 19. - № 1. - С. 147-159.

5. Васильева, Е. Н. Социальная активность пожилых людей в современной России: гендерный аспект / Е. Н. Васильева, Н. А. Скобелина, Н. А. Николенко, Н. В. Дулина // Logos et Praxis. Серия 7: Философия. Социология и социальные технологии. - 2018. - Т. 7. - № 2. C. $44-48$.

6. Долгова, В. М. Адаптация рассматривается как научно-исследовательский феномен: сущность и содержание / В. М. Долгова // Молодой ученый. - 2009. - № 9 (9). - С. 149-152.

7. Двойникова, Е. Ю. Девиантное поведение студентов в процессе социально-психологической адаптации в вузе / Е. Ю. Двойникова // Вестник Самарского государственного технического университета. Серия Психолого-педагогические науки. - 2015. - № 2 (26). - С. $43-49$.

8. Двойникова, Е. Ю. Социально-психологическая адаптация иичности в период глобальных политических и экономических преобразований общества / Е. Ю. Двойникова // Интернет-журнал «Мир науки». - 2017. - Т. 5. - № 3. - С. 1-11. - Режим доступа: URL: https:// cyberleninka.ru/article/n/sotsialno-psihologicheskaya-adaptatsiya-lichnosti-v-period-globalnyh-politicheskih-i-ekonomicheskih-preobrazovaniy-obschestva/viewer (дата обращения: 21.04 .2021 г.).

9. Иванов, С. Ф. Пенсионная реформа-2019: детерминанты, последствия, альтернативы / С. Ф. Иванов // Демографическое обозрение: электронный журнал. - 2019. - Т. 6. - № 2. - С. 6 54. - Режим доступа: URL: https://demreview.hse.ru/article/view/9871/10187 (дата обращения: 23.04.2021 г.)

10. Иванова, А. И. Социально-психологическая адаптация: классификация и механизмы / А. И. Иванова // Вестник Университета. Раздел VI. Педагогика, психология, социология, фииософия. - 2014. - № 9. - С. 255-259.

11. Капица, С. И. Особенности механизма социальной адаптации экономически активного населения к изменениям рынка труда / С. И. Капица // Известия Российского государственного педагогического университета им. А. И. Герцена. - 2009. - № 114. - С. 314-320. 
12. Караяни, А. Г. Психологические последствия войны и социально-психологическая реадаптация участников боевых действий / А. Г. Караяни, Ю. М. Караяни // Вестник ЮжноУрадьского государственного университета. - 2014. - Т. 7. - № 4. - С. 59-66.

13. Кибанов, А. Я. Управление персоналом организации: актуальные технологии найма, адаптации и аттестации / А. Я. Кибанов, И. Б. Дуракова. - М.: КноРус Медиа, 2019. - 466 с.

14. Котлова, А. С. Адаптация персонала на предприятии в современных условиях [Электронный ресурс] / А. С. Котлова, О. А. Попова // Экономика и менеджмент инновационных технологий. - 2014. - № 6(33). - Режим доступа: URL: http://ekonomika.snauka.ru/2014/06/5092 (дата обращения: 12.04.2021 г.).

15. Яемиш, В. В. Подготовка к выходу на пенсию как элемент геронтокультуры [Текст] / В. В. Лемиш // Омский научный вестник. - 2015. - № 4 (14). - С. 126-129.

16. Лукашенко, Д. В. Адаптивная стратегия как основа взаимодействия дичности с социальной средой / Д. В. Аукашенко // Человеческий капитал. - 2014. - № 7(67). - С. 23-31.

17. Аукашенко, Д. В. К проблеме адаптации личности силовых структур / Д. В. Аукашенко // Образование и наука в России и за рубежом. - 2018. - № 10 (Vol. 45). - C. 288-291.

18. Луцุко, Е. А. К вопросу об определении критериев и факторов эффективности адаптации / Е. А. Ауцко // Вестник Санкт-Петербургского университета. - 2008. - № 1. - С. 205-209.

19. Макаренко, Б. И. Адаптация подитических субъектов к вызовам современной политики / Б. И. Макаренко // Коммуникологи. - 2016. - Т. 4. - № 5. - С. 120-129.

20. Макайкина, Н. В. Адаптация персонала на предприятии / Н. В. Макайкина // Молодой ученый. - 2019. - № 43 (281). - С. 181-183. - Режим доступа: URL: https://moluch.ru/ archive/281/63288/ (дата обращения: 04.03.2021 г.).

21. Максимов, А. А. Адаптация как процесс активности и развития субъекта / А. А. Максимов // Акмеология. - 2013. - № 4 (48). - С. 72-76.

22. Максимова, С. Г. Социально-экономические факторы межсубъектной адаптации с позиций трудового опыта старшего поколения / С. Г. Максимова, М. Б. Максимов // Вестник Алтайского государственного аграрного университета. - 2015. - № 1 (123). - С. 165-171.

23. Максимова, А. А. Проблема одиночества в пожилом возрасте / А. А. Максимова, К. Д. Маховицкая, О. В. Ничиженова, Е. В. Соболева // Вестник совета мододых ученых и специалистов Челябинской области. - 2016. -Т. 2. - № 1(12). - С. 38-40.

24. Маркина, Н. А. Подитическая адаптация граждан: опыт эмпирического анадиза / Н. А. Маркина // Известия Тульского государственного университета. Гуманитарные науки. Тула: Изд-во Тульского государственного университета. - 2008. - № 2. - С. 95-102.

25. Мельникова, Н. Н. Классификация стратегий адаптивного поведения / Н. Н. Медьникова // Теоретическая, экспериментальная и практическая психология: сборник научных трудов / под ред. Н. А. Батурина. - Челябинск: ЮУрГУ, 2001. -Т. 3. - С. 16-29.

26. Николенко, Н. А. Самозанятость граждан предпенсионного возраста в условиях формирования цифрового общества / Н. А.Николенко // Вестник Удмуртского университета. Социология. Политология. Международные отношения. - Ижевск: Изд-во Удмуртского государственного университета, 2020. - Т. 4. - Вып. 1. - С. 35-42.

27. Николенко, Н. А. Предпенсионеры на региональном рынке труда: социальные зарисовки о влиянии национальных проектов / Н. А.Николенко, Я. И. Серова // XXII Уральские социологические чтения. Национальные проекты и социально-экономическое развитие уральского региона: материалы Всерос. научно-практич. конф. / под общ. ред. Ю. Р. Вишневского, М. В. Певной. - 2020. - С. 327-332.

28. Реан, А. А. Психология адаптации личности / А. А. Реан, А. Р. Кудашев, А. А. Баранов. - СПб.: Прайм-ЕВРОЗНАК, 2008. - 480 с.

29. Реан, А. А. Локус контроля делинквентной личности / А. А. Реан // Психологический журнал. - 1994. - Т. 5. - № 2. - С. 52-56.

30. Садкова, И. В. Особенности трудоустройства людей / И. В. Садкова // Журнал «Нuman Progress». - 2019. - T. 5. - № 2. - C. 1-9.

31. Слепцова, Е. В. Современные взгляды на адаптацию работника: сущность, виды, функции и факторы адаптации / Е. В. Слепцова, Д. Сапрунова // Международный журнал гуманитарных и естественных наук. - 2020. - № 8 (47). - С. 179-182. 
32. Скрылева, О. В. Социологическая адаптация личности в профессиональном поле деятельности: методологический аспект / О. В. Скрылева // Омский научный вестник. - 2007. № 4(58). - C. 137-140.

33. Смирнова, А. В. Адаптация персонала: ее формы и виды. Особенности адаптации молодых специалистов / А. В. Смирнова, Р. М. Кочеткова, Е. В. Коротина // Вестник УдГТУ, 2017. - № 4. - С. 59-61.

34. Терещенко, А. Г. Анализ процесса социальной адаптации личности к правовому пространству / А. Г. Терещенко, Н. Г. Васильев // Иркутский институт (филиал) ВГУЮ (РПА Минюста России). - Иркутск: Пролог, 2013. - № 1(1). - С. 74-82.

35. Терещенко, А. Г. Социальная адаптация дичности к современным социально-экономическим условиям / А. Г. Терещенко // Известия Байкальского государственного университета. - 2006. - № 2. - С. 84-87.

36. Трошина, Н. В. Виды адаптации современного человека: социально-философский анализ проблемы / Н. В. Трошина // Известия Саратовского университета. Новая серия. Сер.: Философия. Психология. Педагогика. - 2014. - Т. 14. - Вып. 1. - С. 32-34.

37. Усаева, Н. Р. Планирование профессиональной деятельности дюдьми предпенсионного возраста / Н. Р. Усаева // Наука и инновации XXI века: сборник статей по материалам VI Всерос. конф. молодых ученых, 27 сентября 2019 г.; в 3 т. - Сургут: Изд-во Сургутского государственного университета, 2020. -Т. 1. - С. 188-192.

38. Хаустова, А. И. Социально-психологическая адаптация / А. И. Хаустова // Молодой ученый. - 2016. - № 26 (130). - С. 614-617.

39. Хохрина, 3. В. Диалектика стратегий социальной адаптации личности / 3. В. Хохрина, А. А. Машанов, М. В. Ростовцева // Современные проблемы науки и образования. - 2015. № 2-2. - Режим доступа: URL: http://science-education.ru/ru/article/view?id=21725 (дата обращения: 28.04.2021 г.).

40. Черных, Н. А. Предпенсионеры на рынке труда: проблемы занятости и меры поддержки / Н. А. Черных, А. Н. Тарасова, А. Е. Сырчин // Экономика региона. - 2020. - Т. 16. № 4. - C. 1178-1192.

41. Чупрасова, Е. Д. Правовой статус лиц предпенсионного возраста в сфере труда / Е. Д. Чупрасова // Журнал «Е-Sсіо». - 2019. - № 5(32). - С. 66-71.

42. Шабанова, М. А. Социадьная адаптация в контексте свободы / М. А. Шабанова // Социологические исследования. - 1995. - № 9. - С. 81-88.

43. Широких, С. В. Обзор изменений законодательства, регулирующего пенсионное обеспечение в Российской Федерации / С. В. Широких // Социально-экономический и гуманитарный журнал Красноярского ГАУ. - 2019. - № 1(1). - С. 133-143.

44. Шишкин, В. И. Политическая адаптация населения Сибири в XX веке: теоретикометододогические подходы и историографические результаты изучения / В. И. Шишкин // Подитическая адаптация населения Сибири в первой трети XX века: сб. науч. ст. / под ред. В. И. Шишкина. - Новосибирск: Параляель, 2015. - С. 3-44.

45. Щепаньский, Я. Элементарные понятия социологии / Я. Щепанский. - М.: Прогресс, 1969. -240 c. 